\title{
The legal status of animals: a source of their disaster vulnerability
}

Peer Reviewed

\section{Ashleigh Best $^{1}$}

1. University of Melbourne, Melbourne, Victoria.

\section{SUBMITTED}

10 February 2021

\section{ACCEPTED}

16 May 2021

\section{DOI}

www.doi.org/10.47389.36.3.63

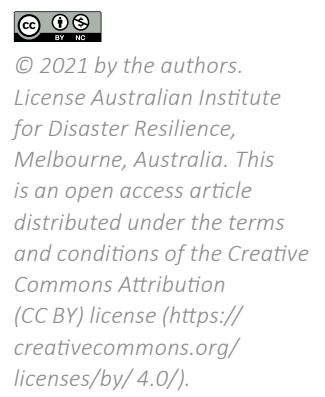

\section{Introduction}

Disasters in recent decades, such as the 2019-20 Australian bushfire season, have made animals' vulnerability to hazards sharply apparent. In so doing, they have prompted governments across the world to improve emergency management measures for animals. Hurricane Katrina, which devastated the Gulf States of the USA in 2005, was a watershed event in this regard (see Travers, Degeling \& Rock 2017). The storm caused the deaths of almost 2000 people (Rhodes et al. 2010) along with hundreds of thousands of companion animals (Baum 2011) and revealed how illequipped emergency response systems were to meet the needs of residents living with animals. In response, the US Congress passed the Pets Evacuation and Transport Standards Act 2006 Pub. L. No. 109-308, 120 Stat 1725 (2006) (PETS Act). This compelled emergency management authorities to consider the needs of individuals evacuating with companion and assistance animals in order to receive certain federal funding. Similarly, following the 2009 Black Saturday Bushfires, the Australian State of Victoria introduced the Victorian Emergency Animal Welfare Plan (Agriculture Victoria 2019). New Zealand also substantially improved provision for animal welfare in its emergency planning framework in the wake of the 2010 and 2011 earthquakes in Canterbury.

Although some scholarly attention has been paid to these developments, and particularly to the PETS Act, there is a dearth of literature examining how the underlying legal status of animals aggravates their vulnerability to disasters. 'Vulnerability' is conceptualised in line with the widely accepted definition posited by Wisner and co-authors (2003, p.11):

...the characteristics of a person or group and their situation that influence their capacity to anticipate, cope with, resist and recover from the impact of a natural hazard (an extreme natural event or process).

On this view, disasters occur when hazards affect vulnerable communities. Rather than focusing on the content and effectiveness of disaster planning instruments for animals, this study uses the vulnerability paradigm to interrogate how the law itself increases animals' susceptibility to hazards. To this end, this paper draws on 4 case studies: Hurricane Katrina, the Canterbury earthquakes, the Black Saturday

\section{Abstract}

The 2019-20 Australian bushfire season had a devastating impact on animals. A report sponsored by the World Wide Fund for Nature (2020) estimates that 3 billion native wild animals were affected by the bushfires, with several species now closer to extinction. Thousands of domesticated farm animals also perished, either as an immediate result of the bushfires or as a consequence of being euthanised with fire-related injuries. In addition, there was concern about the adequacy of arrangements for the evacuation and care of companion animals during the emergency. In these diverse ways, the bushfires brought the profound and multidimensional vulnerability of animals to disaster events into stark focus. Using case studies, this paper examines the role the law plays in contributing to this vulnerability. It investigates how the status of animals as 'property' under law increases their exposure to hazards and affects their priority in disaster planning and response. This paper also scrutinises the extent to which statutory welfare and environmental protections are capable of optimising wellbeing and survival outcomes for animals in disasters. 
bushfires and the 2019-20 Australian bushfire season. This paper begins with a brief survey of the rationales for considering animals in disasters. It then scrutinises how 2 dimensions of animals' legal status amplify or fail to address their disaster risk. The first dimension is their status as property under law. The second is comprised of the provisions that apply to them under animal welfare and environment protection statutes (together, 'statutory protections'). The purpose of this study is to critique animals' existing legal status by interrogating its role in rendering them vulnerable during disasters. Future research might consider the modifications that could be made to this status to improve outcomes for animals in emergencies.

\section{Considering animals in disasters}

Over the past 2 decades, and particularly since Hurricane Katrina, the emergency management literature has reinforced the importance of accounting for the interests of animals during emergencies. In their review of scholarly sources on the management of companion animals in disasters, Travers, Degeling and Rock (2017) observe that research identifies 2 reasons for incorporating companion animals within emergency management plans. First, the bond many share with their companion animals represents a 'risk factor' to human safety and resilience. During a disaster, owners may be reluctant to leave their properties if they cannot take their companion animals with them or might return to check on their animals before it is safe to do so (Heath \& Linnabary 2015). Studies have also confirmed that the loss of companion animals can have adverse psychological consequences and hamper community resilience and recovery in the aftermath of a disaster (Hunt, Al-Awadi \& Johnson 2008). Similarly, concern for the welfare of farm animals can influence human evacuation behaviour (e.g. Glassey \& Wilson 2011), and livestock losses can inflict 'enormous emotional distress' on farming families and communities (Travers, Degeling \& Rock 2017).

Animals are also said to be 'at risk' during disasters (Travers, Degeling \& Rock 2017). This rationale for including animals in disaster planning generally emphasises their sentience and innate (as opposed to only instrumental) value (Travers, Degeling \& Rock 2017). Irvine examines how distinct categories of animals experience varying levels of exposure to hazards and 'are differentially provided opportunities for rescue or escape' (p.6). On this logic, Irvine (2009) contends that emergency planning frameworks are remiss to exclude animals densely confined and reliant on automated food systems in factory farms (p.6). Similarly, White (2012) argues the omission of companion animals from official disaster management frameworks in many jurisdictions overlooks their 'intrinsic value' and entitlement to 'care and respect in their own right' (p.381). Analogous arguments have been made in relation to wildlife, particularly given this group's sensitivity to shifting environmental conditions. For example, Lovvorn (2016) explains that climate change is disrupting weather patterns and terrestrial and marine habitats, and is therefore exterminating species that are unable to adapt. These processes impair ecosystem functions and services (Lovvorn 2016) and jeopardise biodiversity (Clark et al. 2014). Lovvorn (2016) also emphasises the extraordinary suffering they inflict on sentient animals, who have 'no ability to plan, mitigate, or (in many cases) migrate away from the impacts of climate change' (p.40). Rather than characterising measures for animals as merely ancillary to those that safeguard humans, proponents of this rationale argue that animals should be protected from the adverse effects of hazards for their own sakes.

\section{Animals as property: legally exploitable and inferior}

Whereas Western legal systems categorise humans as persons, animals bear the legal status of property (Wise 1996). At common law (the tradition prevailing in Australia) domestic animals are at all times the property of their owners, whereas wild animals only become property when killed or brought under the control of a person (Yanner v Eaton (1999) 201 CLR 351, pp.386-387; note, a similar doctrine exists in the European civil law tradition: see, e.g. Polojac 2014). Some Australian jurisdictions have modified the common law position by passing legislation that vests ownership of all wild animals in the Crown. Regardless of the precise rule in operation, animals in Australia, including wild animals, are either property or capable of becoming property. Consequently, they are not persons.

Categorising animals as property has extensive ramifications for their wellbeing and survival, particularly during disasters. It is this status that allows animals to be used and kept in ways that maximise their value and economic efficiency (Kelch 1998), regardless of whether such practices exacerbate their vulnerability to disasters. The implications of this are particularly significant for agricultural animals. The fact that these animals are property justifies contemporary husbandry practices that increase their exposure to hazards, while failing to make provision for emergency events. According to Crawford (2020), tens of thousands of agricultural animals perished in the 2019-20 Australian bushfire season. In early 2020, harrowing images emerged of scorched carcasses in paddocks and along roadsides in NSW and Victoria. These animals had unsuccessfully attempted to flee (Bell 2020). On Kangaroo Island in South Australia, an astounding 60,000 head of livestock (mostly sheep) died (Government of South Australia 2020). It was precisely the property status of these animals that enabled them to be enclosed in paddocks exposed to the flames.

The effects of confinement are even worse for animals housed in intensive agricultural facilities (Irvine 2009): a practice similarly sanctioned by their property status. As in Australia, animals in New Zealand and the USA are categorised as property under law (Putt v Roster (1682) 2 Mod Rep 318; State v Chambers, 194 La. 1042,1045 (1940)). The first of the Canterbury earthquakes in 2010 resulted in the deaths of 3000 chickens at one layer-hen facility where 2 of the site's 3 stands collapsed (Glassey \& Wilson 2011). While this was a direct consequence of the earthquake, Potts and Gadenne (2014) nonetheless describe the casualties as 'victims of inhumane structural design' (p.224). Hundreds of millions of broiler chickens were estimated to have met a similar fate during Hurricane Katrina. Irvine (2009) argues that, in cases such as this, 'the factory farming system, not the weather alone, 
created disastrous consequences' (p.8). That these birds could be housed in such densely stocked and poorly constructed facilities is attributable to their status as property.

Since animals' property status makes them legally inferior to people, they are usually afforded a low priority in emergency response initiatives. This was evident during Hurricane Katrina where emergency transport and accommodation services widely refused to accept evacuees who were accompanied by their companion animals. One poignant case was that of Snowball: a small white dog forcibly removed from a young boy before he could board an evacuation bus (Zotarelli 2010). This kind of hostility towards animals in emergency policy is symptomatic of animals' subordinate status as property. Baum (2011) argues that this status creates a 'value disparity' between humans and animals, whereby animals have 'less value than humans'; as a consequence, their interests are relegated during emergency rescue and relief operations (p.108). Potts \& Gadenne (2014) similarly observe that, since animals are legally mere 'possessions', they 'are at risk of being treated as "things" or "objects"' under emergency management law (p.7).

Although jurisdictions - including in Australia - have started to integrate animals in disaster planning, their interests remain secondary to those of humans. In response to the recommendations of the 2009 Victorian Bushfires Royal Commission, the Victorian Emergency Animal Welfare Plan (Agriculture Victoria 2019) was introduced. Despite being the first substantial attempt in Australia to safeguard animals in disasters (White 2012), the instrument is highly anthropocentric. Its first guiding principle is that the '[p]rotection and preservation of human life is paramount' (State of Victoria 2019, para. 3.0). South Australia's animal emergency management framework describes the protection of humans in disasters as 'the overarching priority' (Government of South Australia 2018, p.10) and the Western Australian equivalent states that protecting the safety of people is the 'primary aim of emergency response' (Government of Western Australia 2019, p.1). There may be justifications for prioritising humans in disasters. Nonetheless, the subjugation of animal interests, enabled by their status as property and therefore as non-persons, can have profound implications for their survival and wellbeing (Heath \& Linnabary 2015).

Due to their proximity to humans, companion animals derive some benefit from even anthropocentric disaster plans. In contrast, production animals have been largely overlooked by these instruments. Glassey (2020) attributes this to the absence of a 'human-animal bond' in respect of such animals. Irvine (2009) observes that, unlike companion animals, animals on farms firmly 'occupy the "animal" side' of the humananimal divide (p.40). This is evident in New Zealand's National Civil Defence Emergency Management Plan Order 2015 (NZ). Although the plan contemplates the mass evacuation of production animals in writing (cl 140(d)(iii)), this measure is elsewhere described as merely 'aspirational' and not a 'current requirement' (Ministry of Civil Defence and Emergency Management 2015). In Australia, the substantial farm animal casualties during the 2019-20 bushfire season attest to a similar approach. Given the obstacles facing the large-scale transport of animals at short notice (The Senate Finance and Public Administration References Committee 2020), these outcomes are hardly a result of individual negligence or callousness. They are, however, related to these animals' property status, which enables them to be characterised as insurable and replaceable economic goods (see, e.g. Stoddard \& Hovorka 2019).

The legal status of wild animals also has implications for their management in disasters. Concern for the ecological consequences of mass wildlife mortality has bolstered support for wild animal relief efforts. However, as the 2019-20 Australian bushfire season made plain, the status of wild animals as non-persons operates to diminish their interests in emergencies. The exclusion of wildlife from mainstream statutory rescue frameworks (see, e.g. State Emergency and Rescue Management Act 1989 (NSW) s 3(1)) has the potential to create discord between first responders and wildlife rescuers during emergencies. The Final Report of the Royal Commission into National Natural Disaster Arrangements observed that, in jurisdictions where wildlife organisations were integrated in formal emergency management frameworks, wildlife rescue teams received prompt access to fire grounds (Commonwealth of Australia 2020). However, in other states, a lack of coordination between first responders and wildlife rescuers delayed the treatment of injured animals (Commonwealth of Australia 2020).

These structural challenges affecting the management of wildlife were compounded during 2019-20 Australian bushfire season by resource shortages. Referring to public submissions, the Interim Report of the Senate Inquiry into the 2019-20 bushfires noted concern over the 'limited' capability to retrieve and care for affected wildlife in the wake of the disaster (Senate Finance and Public Administration References Committee 2020). Nongovernment organisations also stressed the crucial work wildlife rescuers and carers perform, usually on a voluntary basis (see e.g. Gecko Environment Council (2020)). The incapacitation of wildlife rescuers and under-resourcing of the sector are an expression of the perceived worth of wildlife; as non-persons, wild animals can make very little claim on an emergency management framework designed principally to serve the interests of persons.

\section{Statutory protections for animals: moderate and uncertain}

The treatment of animals is also subject to anti-cruelty and environment protection statutes. These were originally introduced to rectify perceived deficiencies in animals' underlying property status. As the 19th Century Supreme Court of Mississippi observed, the common law 'punished no cruelty' towards animals, 'except insofar as it affected the right of individuals to such property'. It explained that animal welfare statutes operated to 'remedy this defect' (Stephens v. State, 65 Miss. 329, 331 (1888)). Modern wildlife protection and biodiversity conservation laws were likewise first introduced to slow the depletion of wild animal populations due to unrestricted hunting and trapping practices (Bowman, Davies \& Redgwell 
2010). Both anti-cruelty and wildlife conservation laws were motivated by anthropocentric concerns: namely, preserving society's moral fibre by denouncing acts of gratuitous cruelty against live creatures (Ibrahim 2006) and ensuring a sustainable game harvest. Nonetheless, these bodies of legislation represent some of animals' most substantial sources of legal protection (Frasch et al. 1999, White 2013).

While welfare legislation provides animals with some material benefit, it is only moderately effective in protecting them from the adverse effects of natural hazards. Its provisions generally impose unexacting and meagre obligations in order to reduce disruption to an individual's enjoyment of their proprietary rights. Welfare laws often demand only the minimum standards necessary to keep animals alive and in an adequate state of health. Consequently, they fail to address the vulnerability to which animals are exposed as a result of their property status.

As possessions, animals - including dogs - are often lawfully permitted to be tethered, at least in certain circumstances. This practice can detrimentally prevent animals from escaping hazards, such as floodwaters (Glassey 2019). In Louisiana, legislation now prohibits the tethering of cats and dogs in 'extreme weather conditions' in designated emergency areas (LA Rev Stat § 3:2362 (2018)). However, no such law was in place at the time of Hurricane Katrina. As the storm approached, the Society for the Prevention of Cruelty to Animals called for residents in threatened regions not to confine animals left behind on properties (McNabb 2007). Contrary to this advice, owners tied their animals to fence posts outside their homes before evacuating; some eventually drowned in floodwaters (Glassey 2019).

Other jurisdictions are yet to follow Louisiana in prohibiting the tethering of animals during disasters. Legislation in Victoria provides that animals may only be tethered where certain criteria are met, including that they have access to water and sufficient shade (Prevention of Cruelty to Animals Regulations 2019 (Vic) reg 7(1)). The Regulations are silent about the need for favourable weather conditions. The Victorian Code of Practice for the Tethering of Animals (Revision 2) provides that '[a]nimals should never be tethered in conditions where they are vulnerable to heatwaves, severe cold or driving rain'. As the code is advisory, its legal relevance is limited (see Prevention of Cruelty to Animals Act 1986 (Vic) s 6(1)(b)). At least one local council in New Zealand prohibits the confinement of dogs in extreme weather conditions (Kapiti Coast District Council Dog Control Bylaw 2019 cl 7.1(e)). However, the New Zealand Government has not introduced legislation to this effect (Glassey 2019; cf Animal Welfare (Care and Procedures) Regulations 2018 (NZ) regs 16 and 18). Nevertheless, New Zealand prohibits the confinement of animals in a manner that causes them unreasonable or unnecessary pain or distress under the Animal Welfare Act 1999 (NZ) (s 23(1)).

Statutory welfare protections likewise only marginally mitigate the vulnerability of agricultural animals to natural hazards. In Australia, the welfare of farm animals is usually governed by regulatory schemes (Bruce 2012). These instruments make only rudimentary provision for the protection of animals in hazardous conditions. They leave more systemic drivers of their vulnerability, such as confinement, poor infrastructure design or the holding of animals in disaster-prone areas, largely unaddressed. For example, during the Black Saturday bushfires, the Code of Accepted Farming Practice for the Welfare of Cattle (Vic) required herds to be protected from climatic extremes and heat stress 'as far as practical', be provided with sufficient feed and water and be kept behind 'adequate fire breaks' (cll 5.1, 3.1, 2.1, 5.3). The scale and ferocity of the bushfires made these requirements largely redundant, as more than 8000 agricultural animals were killed during the bushfires (Victorian Parliament 2010). The number of farm animal casualties during the 2019-20 summer bushfires was tenfold; these animals enjoyed similar protections to those affected by the Black Saturday bushfires (e.g. Animal Welfare Regulations 2012 (SA) regs 63(1), 74(1)).

Similarly, during the Canterbury earthquakes, minimum housing requirements for poultry birds (Animal Welfare (Layer Hens) Code of Welfare 2005 (NZ) Minimum Standard 3(b)) proved futile as the September 2010 earthquake devastated layerhen facilities. Rules requiring dairy cows to be protected from adverse weather conditions (Animal Welfare (Dairy Cattle) Code of Welfare 2010 (NZ) Minimum Standard 6(a)) also became ineffective as animals held on properties near the fault line suffered fractured bones and were humanely destroyed. In these ways, the modest nature of statutory welfare protections left agricultural animals with limited tangible support during the relevant disasters.

The inadequacy of statutory environmental protections came into sharp focus during the 2019-20 Australian bushfire season bushfires. The ecological catastrophe revealed that the federal Environment Protection and Biodiversity Conservation Act (Cth) (EPBC Act) and state and territory analogues insufficiently protect crucial features of wildlife habitat. In 2020, a review of the EPBC Act found that it has produced a patchwork of management interventions which 'fail to deliver at a system scale' (Samuel 2020, p.128). A recent issues paper concerning the Wildlife Act 1975 (Vic) similarly observed that it does not 'account for indirect threats such as the destruction of wildlife habitat' (Peterson et al. 2021). These shortcomings were particularly consequential for wildlife during the 2019-20 Australian bushfire season: the availability of unburnt habitat and wildlife corridors were identified as factors directly affecting wild animal mortality during the fires (van Eeden et al. 2020). Land clearing activities conducted in accordance with previously approved development applications were also nominated as an 'anthropogenic factor at play in the immediate post-fire environment' that influenced the survival of wildlife (van Eeden et al. 2020).

The operation of statutory protections for animals can also become uncertain in disasters. During the Black Saturday bushfires and the Canterbury earthquakes, owners of companion animals were obliged to provide ill and injured animals with appropriate treatment (Animal Welfare Act 1999 (NZ) s 11; Prevention of Cruelty to Animals Act 1986 (Vic) s 9(1)(i)). However, during both disasters, road blocks and limited resources made it difficult for owners to secure effective and timely veterinary assistance (Potts \& Gadenne 2014, Animal Aid 2009). Similarly, 
welfare legislation in these jurisdictions and in Louisiana at the time of Hurricane Katrina prohibited the abandonment of animals (La Rev Stat Ann § 14:102 (2005); City of the New Orleans Code of Ordinances Sec. 18-2; see Animal Welfare Act 1999 (NZ) s 10; Prevention of Cruelty to Animals Act 1986 (Vic) s 9(h)). Desperate circumstances left many owners with no choice but to part with them though.

While failure to procure veterinary treatment for animals and instances of animal abandonment might ordinarily constitute breaches of welfare legislation, the circumstances in which this conduct took place complicates the law's application. White (2012) argues that, in Australia, statutory welfare protections are likely displaced or tempered in the disaster context. The concept of 'cruelty' is usually associated with behaviour that qualifies as 'unjustifiable, unnecessary or unreasonable' (White 2012, p.387). For White, 'coping with the demands of a disaster will be relevant to the scope of a reasonable excuse' (White 2012, p.387). The statutory protections that applied to companion animals during Hurricane Katrina, the Canterbury earthquakes and the Black Saturday bushfires did not use explicit words of qualification when describing the offences of abandonment or failure to provide for an animal's needs. However, it is unlikely that these provisions continued to bind animal owners with full force during the disasters. The final report of the 2009 Victorian Bushfires Royal Commission affirmed that is was for individuals to 'decid[e] what to do with pets and other animals during an evacuation or when defending a property' (2010, p.353). Irvine (2009) also expresses the view that prosecutions for animal abandonment would have been unlikely in the difficult circumstances of Hurricane Katrina. As this demonstrates, disasters can obscure the application of, and culpability for, contraventions of statutory welfare protections.

\section{Conclusions}

Law is increasingly used to improve disaster preparedness and response, including for animals. A series of disaster planning instruments has been introduced across jurisdictions to optimise welfare outcomes in disasters. While these plans are a welcome development, this study contends that attention must also be paid to the various ways in which animals' underlying legal status contributes to their vulnerability. As the paper examines, 2 key components of this status amplify or fail to rectify animals' susceptibility to the adverse effects of hazards. Animals' property status allows them to be treated in ways that elevate their risk during disasters. It also relegates them to a state of legal inferiority. At the same time, the modest and fluid nature of statutory protections for animals hinder their effectiveness in the extreme context of a disaster. Since its objective was to describe the myriad ways in which the existing status of animals under law makes them vulnerable during disasters, the paper does not consider alternative forms this status might take.

Future research might recommend the abolition of animals' status as property and the institution of a new status such as personhood. Alternatively, it might propose the introduction of robust statutory frameworks for animal welfare and the preservation of habitat, both in ordinary conditions and during emergencies, which comprehensively address the adverse effects of their property status. Whatever solution may be explored, this paper provides one point of departure for future inquiry by diagnosing certain features of animals' existing legal status that constitute them vulnerable to disasters.

\section{Acknowledgment}

This research was supported by a Commonwealth Government scholarship. The author is grateful to the 2 anonymous peer reviewers for their incisive feedback, and to Professor Christine Parker and Professor Lee Godden for their instruction and encouragement.

\section{References}

Animal Aid 2009, Submission No 002.016.0268_R, The 2009 Victorian Bushfires Royal Commission.

Agriculture Victoria 2019, Victoria Animal Emergency Welfare Plan (Revision 2).

Baum M 2011, "Room on the ark?" The Symbolic Nature of US Pet Evacuation Statutes for Nonhuman Animals, in Freeman C, Leane E and Watt Y (eds), Considering Animals: Contemporary Studies in Human-Animal Relations, Ashgate Publishing, Farnham, United Kingdom.

Bell S R 2020, Farmers impacted by bushfires count 'heartbreaking' cost as livestock losses climb, ABC News, 7 January. At: www.abc. net.au/news/2020-01-07/farmers-recount-heartbreaking-toll-ofbushfire-livestock-losses/11844696 [10 February 2021].

Bowman M, Davies P \& Redgwell C 2010, Lyster's International Wildlife Law, Cambridge University Press, Cambridge.

Bruce A 2012, Animal Law in Australia: An Integrated Approach, LexisNexis, NSW.

Clark N E, Lovell R, Wheeler B W, Higgins S L, Depledge M H \& Norris K 2014, Biodiversity, cultural pathways, and human health: a framework, Trends in Ecology and Evolution, vol. 29, no. 4, pp.198-204

Crawford J 2020, Effect of the Australian bushfires on our vets, Veterinary Record, vol. 186, no. 6, p.193.

Commonwealth of Australia 2020, Royal Commission into National Natural Disaster Arrangements 2020, Final Report. At: https://naturaldisaster.royalcommission.gov.au/publications/ royal-commission-national-natural-disaster-arrangements-report [30 May 2021].

Francione G L 1996, Animals as Property, Animal Law, vol. 2, pp.i-vi.

Frasch P, Otto S, Olsen K \& Ernest P 1999, State Animal Cruelty Statutes: An Overview, Animal Law, vol. 5, pp.75-79.

Gecko Environment Council 2020, Submission No 88, Senate Finance and Public Administration References Committee, Lessons to be learned in relation to the Australian bushfire season 2019-2020. 
Glassey S \& Wilson T 2011, Animal welfare impact of the 4 September 2010 Canterbury (Darfield) earthquake, Australasian Journal of Disaster and Trauma Studies, vol. 2, pp.49-59.

Glassey S 2019, No Animal Left Behind: A report on animal inclusive emergency management law reform, Animal Evac NZ, New Zealand.

Glassey S 2020, Animal Welfare and Disasters, in W R Thomson et al. (eds), Oxford Research Encyclopedia of Politics, Oxford University Press, USA.

Government of South Australia, Independent Review into South Australia's 2019-2020 Bushfire Season (June 2020).

Government of South Australia, Managing Animals in Emergencies: A Framework for South Australia, 28 June 2018.

Government of Western Australia 2019, State Support Plan: Animal Welfare in Emergencies, August 2019.

Heath S E \& Linnabary R D 2015, Challenges of Managing Animals in Disasters in the US, Animals, vol. 5, no. 2, pp.173-192.

Hunt M, Al-Awadi H \& Johnson M 2008, Psychological Sequelae of Pet Loss Following Hurricane Katrina, Anthrozoos, vol. 21, no. 2, pp.109-121.

Ibrahim DM 2006, The Anti-Cruelty Statute: A Study in Animal Welfare', Journal of Animal Law and Ethics, vol. 1, pp.175-203.

Irvine L 2009, Filling the Ark: Animal Welfare in Disasters, Temple University Press, Philadelphia, PA.

Kapiti Coast District Council Dog Control Bylaw 2019.

Kelch T G 1998, Toward a Non-Property Status for Animals, New York University Environmental Law Journal, vol. 6, no. 3, pp.531-585.

Lovvorn J 2016, Climate Change Beyond Environmentalism Part I: Intersectional Threats and the Case for Collective Action, Georgetown Environmental Law Review, vol. 29, no. 1, pp.1-68.

McNabb M 2007, Pets in the Eye of the Storm: Hurricane Katrina Floods the Courts with Pet Custody Disputes, Animal Law, vol. 14, no. 1, pp.71-108.

Ministry of Civil Defence and Emergency Management, Analysis of Submissions: Revised National Civil Defence Emergency Management Plan, June 2015.

New South Wales, Agriculture and Animal Services Functional Area Supporting Plan, January 2017.

Peterson D, Beausoleil N, Freiberg A and Pascoe J 2021, Independent Review of the Wildlife Act 1975 Issues Paper, 28 April 2021.

Polojac M 2014, Gaius, Hadzic and Occupatio of Wild Animals Classical Roman Law in the Serbian Civil Code, Fundamina, vol. 20, no. 2, pp.738-747.

Potts A \& Gadenne D 2014, Animals in Emergencies, Canterbury University Press, Christchurch.

Rhodes J, Chan C, Paxson C, Rouse CE, Waters M \& Fussell E 2010, The Impact of Hurricane Katrina on the Mental and Physical
Health of Low-Income Parents in New Orleans, American Journal of Orthopsychiatry, vol. 80, no. 2, pp.237-247.

Samuel G 2020, Independent Review of the EPBC Act 2020. Final Report. Department of Agriculture, Water and the Environment, Canberra, Australia.

State of Victoria, Victorian Emergency Animal Welfare Plan, October 2019.

Stoddard E A \& Hovorka A 2019, Animals, vulnerability and global environmental change: The case of farmed pigs in concentrated animal feeding operations in North Carolina, Geoforum, vol. 100, pp.153-165.

The Senate Finance and Public Administration References Committee 2020, Lessons to be learned in relation to the Australian bushfire season 2019-2020 Interim Report.

Travers C, Degeling C \& Rock M 2017, Companion Animals in Natural Disasters: A Scoping Review of Scholarly Sources, Journal of Applied Animal Welfare Science, vol. 20, no. 4, pp.324-343.

van Eeden LM, Nimmo D, Mahony M, Herman K, Ehmke G, Driessen J, O'Connor J, Bino G, Taylor M \& Dickman CR 2020, Impacts of the unprecedented 2019-2020 bushfires on Australian animals. Report prepared for WWF-Australia, Ultimo NSW.

Victorian Parliament 2010, The 2009 Victorian Bushfires Royal Commission Final Report. At: http://royalcommission.vic.gov.au/ Commission-Reports/Final-Report.html [30 May 2021].

White S 2013, British Colonialism, Australian Nationalism and the Law: Hierarchies of Wild Animal Protection, Monash University Law Review, vol. 39, no. 2, pp.452-472.

White S 2012, Companion Animals, Natural Disasters and the Law: An Australian Perspective, Animals, vol. 2, pp.380-394.

Wise S M 1996, The Legal Thinghood of Nonhuman Animals, Boston College Environmental Affairs Law Review, vol. 23, no. 3, pp.471-546.

Wisner B, Blaikie P, Cannon T \& Davis I 2003, At Risk: Natural Hazards, People's Vulnerability, and Disasters, Routledge, 2nd ed, London.

World Wide Fund for Nature 2020, Interim Report. At: www.wwf.org.au/ArticleDocuments/353/Animals\%20 Impacted\%20Interim\%20Report\%2024072020\%20final.pdf. aspx?OverrideExpiry=Y [30 May 2021].

Zotarelli L K 2010, Broken Bond: An Exploration of Human Factors Associated with Companion Animal Loss During Hurricane Katrina, Sociological Forum, vol. 25, no. 1, pp.110-122.

\section{About the author}

Ashleigh Best is a PhD candidate at the Melbourne Law School. She completed a first-class honours degree with the university medal in law at UTS. Ashleigh also holds qualifications in social inquiry, legal practice and higher education. 